\title{
0 programa de promoção da sustentabilidade de espaços sub-regionais: um estudo de caso sobre a mesorregiáo Grande Fronteira do Mercosul
}

\begin{abstract}
Resumo
Este trabalho tem por finalidade apresentar o encadeamento das políticas públicas federais que possibilitaram a criação da Mesorregião Grande Fronteira do MERCOSUL. Informa-se neste conteúdo uma visão geral da Política Nacional de Desenvolvimento Regional (PNDR), sob critérios do Programa de Promoção da Sustentabilidade de Espaços Sub-Regionais (PROMESO), que tem como principal objetivo induzir a atuação integrada do Governo Federal em novas escalas espaciais, preferencialmente em sub-regiões, e descreve-se a Mesorregião Grande Fronteira do MERCOSUL.
\end{abstract}

Palavras-chave: Desenvolvimento mesorregional. PROMESO. Políticas públicas.

\begin{abstract}
This paper aims at presenting the sequence of the federal public policies that enabled a creation the Mesoregion Grande Fronteira do MERCOSUL. Within this context, a general overview of the National Policy for the Regional Development (PNDR), under the Program for Promotion of Subregional Sustainable Space's criteria (PROMESO), whose main objective induce the integrated performance of the federal government in new spatial scales, preferably in subregional and describe the Mesoregion Grande Fronteira do MERCOSUL.
\end{abstract}

Keyword: Mesoregion development. PROMESO. Public policies.

\section{Introdução}

Com o intuito de diminuir as desigualdades regionais, o Ministério da Integração Nacional lançou, a partir de 2004, a Política Nacional de Desenvolvimento Regional (PNDR), que possui o duplo propósito de reduzir as desigualdades regionais e de ativar os potenciais de desenvolvimento das regiões brasileiras, explorando a imensa diversidade que se observa em nosso país de dimensões continentais.

Entre as políticas públicas implementadas, destaca-se o Programa Nacional de Promoção da Sustentabilidade de Espaços Sub-Regionais (PROMESO).

\footnotetext{
${ }^{1}$ Mestre em Políticas Sociais e Dinâmicas Regionais. stefano_demarco@hotmail.com

2 Professor do Programa de Pós-Graduação Mestrado Profissional em Políticas Sociais e Dinâmicas Regionais (Unochapecó). Doutor em Desenvolvimento Rural. claudiomaia.dr@hotmail.com
} 
O foco é as preocupações incidirem sobre a dinamização das regiões e a meIhor distribuição das atividades produtivas no território, e, também, com este propósito, é que nasce o conceito de Mesorregião Grande Fronteira do Mercado Comum do Sul (MERCOSUL), através da criação do Fórum que abrange desde o noroeste do Rio Grande do Sul, oeste de Santa Catarina até o sudoeste do Paraná, compreendendo 396 municípios, com uma área total de $139.282,5 \mathrm{~km}^{2}$.

Historicamente, esta região possui traços de um desenvolvimento tardio, o que a difere das demais regiões do Sul do Brasil, como é o caso, por exemplo, das regiões litorâneas, que tiveram outro tipo de colonização e visivelmente apresentam um desenvolvimento maior em relação à Mesorregião Grande Fronteira do MERCOSUL.

Conforme Lins (2007), analisando o estado de Santa Catarina, houve diferentes tipos de colonização, as quais ficam evidenciadas pelas especializações de cada uma das regiões, sendo que a preocupação em estudar o fenômeno ocorrido na Mesorregião Grande Fronteira do MERCOSUL é muito menor.

\begin{abstract}
Para mencionar alguns traços mais salientes, o Vale do Itajaí assistiu à modelagem de um aglomerado têxtil-vestuarista centrado em Blumenau, o Norte-Nordeste concentrou atividades metal-mecânicas (em Joinville e em Jaraguá do Sul) e moveleiras principalmente em São Bento do Sul) e o Sul (Criciúma em primeiro lugar) tornou-se reduto de importante produção cerâmica de pisos e azulejos. Todavia essas realidades têm sido pesquisadas com certa freqüência, e o Oeste, cuja ocupação efetiva começou apenas no início do século XX, parece ter sido menos estudado (LINS, 2007, p. 10).
\end{abstract}

O processo de criação das regiões diferenciadas coloca possibilidades e desafios que devem ser assumidos de forma solidária. Os diferentes contextos dos municípios e regiões, com as suas particularidades, exigem políticas públicas capazes de responder adequadamente às diversas necessidades advindas dessa diversidade. A gestão pública, como instrumento de ação política, deve buscar sempre a construção de uma sociedade mais equitativa e democrática (FELICETTI; MOROSINI, 2009, p. 13).

Para descrever as informações referentes à política pública que culminou com a implantação da Mesorregião Grande Fronteira do MERCOSUL, foi aplicada a pesquisa exploratória, que proporciona maior familiaridade com o problema, com vistas a torná-lo mais explícito, ao utilizá-la, permite-se a obtenção de novos conhecimentos no campo da realidade social. Esta modalidade contempla a busca de informações na literatura científica e a comparação com a realidade observada (GIL, 2010, p. 27). Como hipóteses condutoras desta reflexão, adotam-se a importância da implantação da Mesorregião Grande Fronteira do MERCOSUL, assim como a existência da necessidade da diferenciação mesorregional para o desenvolvimento socioeconômico local. Esta pesquisa exploratória empregou os métodos bibliográficos e documentais para atingir os seus objetivos.

\title{
20 Programa de Promoção da Sustentabilidade de Espaços Sub-Regionais (PROMESO)
}

O Brasil, um país com dimensões continentais, é reconhecido pela sua diversidade geográfica, étnica e cultural, mas, sobretudo, por uma diversidade social e econômica preocupantes, dados os indicadores de concentração de renda e desigualdades regio- 
nais, que ainda se apresentam como desafios à sociedade brasileira na mitigação dessas diferenças. Sendo assim, concebida pelo Ministério da Integração Nacional, foi implantada a Política Nacional de Desenvolvimento Regional (PNDR), a fim de proporcionar ferramentas e instrumentos para o desenvolvimento regional, com uma inserção social e econômica, valorizando o potencial endógeno de uma determinada mesorregião, para obter impactos sociais e, de modo geral, importância no cenário nacional (BRASIL, 2009, p. 5).

Seguindo as diretrizes da Política Nacional de Desenvolvimento Regional (PNDR), que visa dirimir substancialmente as desigualdades regionais, foi implementado o Programa de Promoção da Sustentabilidade de Espaços Sub-Regionais (PROMESO), com o intuito de reafirmar os potenciais endógenos das mesorregiões diferenciadas.

O Programa de Promoção da Sustentabilidade de Espaços Sub-Regionais (PROMESO) orienta-se pelas diretrizes da Política Nacional de Desenvolvimento Regional (PNDR), que busca a redução das desigualdades regionais e atua a partir de dois eixos principais: a organização social e a ativação econômica. $O$ primeiro eixo volta-se ao estímulo e fortalecimento dos fóruns mesorregionais para que sejam canais de participação da sociedade civil na definição de ações a serem contempladas com investimentos públicos. O eixo da ativação econômica se dá por meio do fomento aos Arranjos Produtivos Locais identificados como prioritários nas Mesorregiões Diferenciadas e nas Regiões Integradas de Desenvolvimento-RIDEs (BRASIL, 2009, p. 10).

Em sintonia com a Política Nacional de Desenvolvimento Regional (PNDR), cuja escala prioritária é a mesorregional, os espaços sub-regionais contemplados pelo PROMESO incluem as Mesorregiões Diferenciadas - caso específico da Mesorregião Grande Fronteira do MERCOSUL - e as Regiões Integradas de Desenvolvimento (RIDEs). As Mesorregiões Diferenciadas são espaços contínuos, formados por territórios de uma ou mais unidades da federação, o que as tornam distintas das mesorregiões adotadas pelo Instituto Brasileiro de Geografia e Estatística (IBGE), que são desenhadas como base nas fronteiras estaduais. Embora possam abranger territórios de mais de um estado, as Mesorregiões Diferenciadas são menores que as Macrorregiões determinadas pelo IBGE. Como consequência, as Mesorregiões Diferenciadas são formadas por territórios e municípios que apresentam identidades físicas, econômicas, sociais e culturais e permitem a configuração de um arranjo político-institucional com participação da sociedade civil, num processo de busca de coordenação e efetividade das ações territoriais das políticas públicas de diferentes esferas de poder. Com o intuito de contribuir para a redução das desigualdades regionais e para a promoção de dinâmicas mais inclusivas de desenvolvimento, esse arranjo político-institucional tem o papel de definir, de forma participativa, os objetivos específicos e identificar as potencialidades a serem fortalecidas e as vulnerabilidades a serem dirimidas. A ênfase inicial foi dada a partir da necessidade de organização e de capacitação da sociedade nesses espaços para o encaminhamento de suas demandas, aproveitando toda a experiência acumulada pelas sub-regiões brasileiras (BRASIL, 2009, p. 10).

São objetivos do PROMESO: a) induzir a atuação integrada do Governo Federal em novas escalas espaciais, preferencialmente em sub-regiões; b) promover a identificação de demandas e soluções à chamada problemática regional, com a participação efetiva da sociedade civil, que, para tanto, deve estar organizada e legitimamente re- 
presentada; c) buscar a superação dos desequilíbrios com base no fomento a todas as regiões que apresentem potencialidades e ativos - capital humano e social, parcerias, capacidade de construírem planos e pactos, redes de cooperação entre agentes econômicos, cooperação entre instituições públicas e privadas (BRASIL, 2009).

Na Figura 1, apontam-se os Arranjos Produtivos Locais (APLs) oportunizados pelo Programa de Promoção da Sustentabilidade de Espaços Sub-Regionais (PROMESO), que possibilitaram a criação das seguintes Mesorregiões Diferenciadas.

\section{Figura 1 - Arranjos Produtivos Locais nas

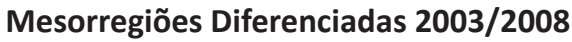

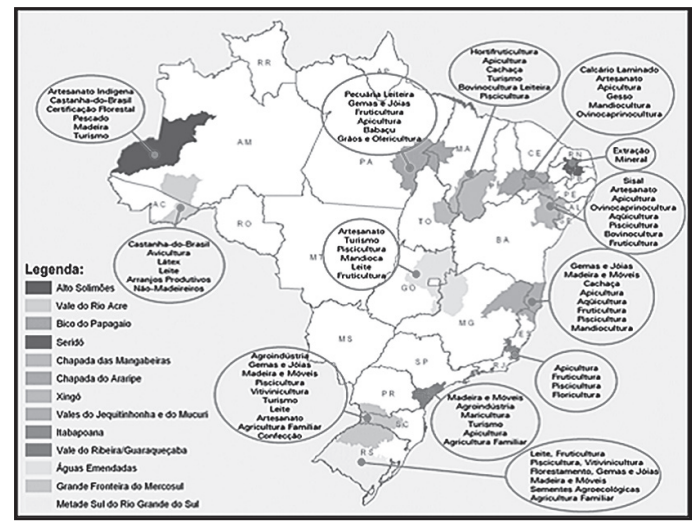

Fonte: Brasil (2009, p. 46).

Como se observa na Figura 1, esta Política Nacional de Desenvolvimento Regional (PNDR) proporcionou treze mesorregiões, distribuídas pelo território nacional, sendo elas: Alto do Solimões, Vale do Rio Acre, Bico do Papagaio, Seridó, Chapada das Mangabeiras, Chapada do Araripe, Xingó, Vale do Jequitinhonha/Mucuri, Itabapoana, Vale do Ribeira/Guaraqueçaba, Águas Emendadas, Grande Fronteira do MERCOSUL e Metade Sul do Rio Grande do Sul.

Por ser um programa com foco na gestão de um processo de desenvolvimento amparado no estímulo ao potencial endógeno e nas especificidades econômicas, sociais e culturais de determinado espaço, a atuação do PROMESO tem início na organização social, que deve ser institucionalizada e consolidada em instâncias legítimas de articulação e integração dos atores locais, governamentais e não governamentais (fóruns, agências, conselhos, consórcios, etc.). A ação do PROMESO prevê, ainda, a criação de um sistema apropriado de organização e disseminação de informações (BRASIL, 2009, p. 12).

Deve-se levar em consideração, também, que os fóruns são espaços de discussão, responsáveis pela identificação, pela priorização, pelo encaminhamento das demandas locais e pelo acompanhamento da implementação de projetos, para melhor destinação de recursos públicos. 
São fundamentais no processo de articulação e integração dos atores locais, em nível de governo (prefeituras e câmaras municipais, órgãos estaduais e federais) e de sociedade civil (organizações indígenas, de produtores rurais e extrativistas, entre outros), devido à proximidade com essas entidades e ao maior conhecimento das realidades locais.

O fortalecimento destas novas institucionalidades, conjugado com a construção de um processo participativo e legítimo de empoderamento de atores, a partir de base territorial, que tem por objetivo a instituição de mecanismos de gestão compartilhada, configura-se como uma mudança de paradigma em relação ao modelo clássico de desenvolvimento regional no Brasil. A estratégia deste novo processo de desenvolvimento almeja a equidade social da sustentabilidade, da inclusão, da participação da sociedade, do acesso ao mercado, da igualdade racial e de gêneros, e de outros aspectos, como alcance de autoestima e dignidade cidadã, relacionados ao desenvolvimento humano (BRASIL, 2009).

Para delimitar as áreas em que se enquadravam a formação destas novas mesorregiões, foi determinada uma tipologia pelo Programa de Promoção da Sustentabilidade de Espaços Sub-Regionais (PROMESO), definindo os seus critérios. E, para atingir os objetivos propostos pela Política Pública, foram cunhados os seus princípios norteadores.

No Quadro 1 (inserido na próxima página), os princípios e critérios do PROMESO.

Com estas prerrogativas, surgiu a Mesorregião Grande Fronteira do MERCOSUL, através da criação do Fórum de Desenvolvimento Integrado e Sustentável da Mesorregião da Grande Fronteira do MERCOSUL, com os principais projetos, tais como os de

fortalecimento de agroindústrias familiares; desenvolvimento do Arranjo Produtivo Local (APL) de móveis; sinalização turística, na região das missões jesuíticas; fortalecimento da piscicultura; fortalecimento da viticultura; lapidação e artesanato mineral, e apoio ao setor lácteo (BRASIL, 2013, p. 1), tendo como propósito reduzir as desigualdades regionais e ativar os potenciais de desenvolvimento desta região, explorando as particularidades locais (BRASIL, 2013, p. 1-2).

\section{A Mesorregião Grande Fronteira do MERCOSUL}

A criação oficial do Fórum de Desenvolvimento da Mesorregião Grande Fronteira do MERCOSUL aconteceu na data de 28 de novembro de 2002 e se constituiu como sociedade civil de direito privado, sem fins lucrativos e com duração indeterminada.

De acordo com seu estatuto, o Fórum tem como finalidade articular e estimular a ação conjunta das entidades públicas, privadas e da sociedade civil, representativas dos diferentes segmentos da sociedade mesorregional, bem como promover estudos, opinar sobre políticas e formular propostas destinadas à promoção do desenvolvimento integrado e sustentável, reduzindo as disparidades inter e intrarregionais no âmbito da Mesorregião Grande Fronteira do MERCOSUL (MESOMERCOSUL, 2013). 


\section{Quadro 1 - Princípios e Critérios do PROMESO}

\begin{tabular}{|c|c|}
\hline PRINCÍPIOS NORTEADORES DO PROMESO & $\begin{array}{l}\text { CRITÉRIOS PARA A CRIAÇÃO DE } \\
\text { NOVAS MESORREGIÕES }\end{array}$ \\
\hline $\begin{array}{l}\text { - Contribuição para uma nova agenda do desenvolvimento } \\
\text { sustentável, que pressupõe eficiência econômica, equidade } \\
\text { social e sustentabilidade ambiental a partir de uma concepção } \\
\text { humanista do desenvolvimento; } \\
\text { - Necessidade de ampliar os processos de descentralização } \\
\text { política no país, com mais controle social e transparência; } \\
\text { - Promoção de novos valores, tais como a participação com } \\
\text { responsabilidade social, o exercício pleno da cidadania, } \\
\text { a importância da visão de futuro e o fortalecimento do } \\
\text { protagonismo da sociedade a partir das regiões; } \\
\text { - Cooperação entre os atores sociais, os agentes produtivos e } \\
\text { as instituições públicas e a capacidade de pactuação de um } \\
\text { projeto coletivo; } \\
\text { - Compreensão de que homens e mulheres são sujeitos de sua } \\
\text { história, protagonistas das mudanças sociais e são os recursos } \\
\text { mais estratégicos do desenvolvimento econômico e político; } \\
\text { - Ação pedagógica que provoque o empoderamento e a } \\
\text { autonomia dos atores locais no processo de desenvolvimento } \\
\text { regional; } \\
\text { - Reconhecimento da importância das parcerias baseadas no } \\
\text { senso de propósito compartilhado e na agregação mútua de } \\
\text { valor; }\end{array}$ & $\begin{array}{l}\text { - Existência de atores que possam } \\
\text { servir como catalisadores do } \\
\text { processo de implantação da } \\
\text { mesorregião; } \\
\text { - Pré-estabelecimento de um desenho } \\
\text { territorial, para verificação, com } \\
\text { os atores mesorregionais, da sua } \\
\text { viabilidade em função das redes de } \\
\text { articulação existentes na área; } \\
\text { - Identificação de elementos } \\
\text { integradores (dimensões } \\
\text { econômicas, físico-ambiental, } \\
\text { sociocultural e político-institucional); } \\
\text { - Consideração de outras } \\
\text { regionalizações propostas por } \\
\text { Governos Estaduais ou pelo próprio } \\
\text { Governo Federal e, principalmente, } \\
\text { pela sociedade civil organizada. }\end{array}$ \\
\hline
\end{tabular}

Fonte: Brasil (2009, p. 15-16).

Analisando os princípios que regem as ações do Fórum, percebe-se que se trata especificamente de questões voltadas ao desenvolvimento sustentável, tendo em vista que prioriza fatores ligados à autonomia politico-institucional, à pluralidade e à busca de consensos, à formação de parceira e cooperação, à integração e à articulação entre entidades públicas, privadas e da sociedade civil.

Segundo Bandeira (1999, p. 16):

O desenvolvimento participativo e a boa governância relacionam-se da forma seguinte: o desenvolvimento participativo, com seu foco central na melhoria da qualidade da participação pelas sociedades locais, facilitando o atingimento do desenvolvimento sustentável e auto-suficiente e da justiça social, é uma forma importante de desenvolvimento orientado para as pessoas.

Desta forma, a Mesorregião Grande Fronteira do MERCOSUL é composta pelo sudoeste do Paraná, oeste de Santa Catarina e o norte do Rio Grande do Sul, abrangendo 396 municípios, sendo 223 no norte do Rio Grande do Sul, 131 no oeste de Santa Catarina, e 42 no sudoeste do Paraná, com área total estimada de 139.282,5 mil quilômetros quadrados e população de, aproximadamente, quatro milhões de habitantes. A despeito dessa Mesorregião ter uma ocupação considerada antiga, o seu contingente de urba- 
nização é relativamente baixo, em comparação com o resto do país, em torno de $65 \%$, sendo que apresenta uma parcela significativa da população na zona rural (MESOMERCOSUL, 2013). A Figura 2 ilustra os limites geográficos da Mesorregião Grande Fronteira do MERCOSUL.

Figura 2 - A Mesorregião Grande Fronteira do MERCOSUL

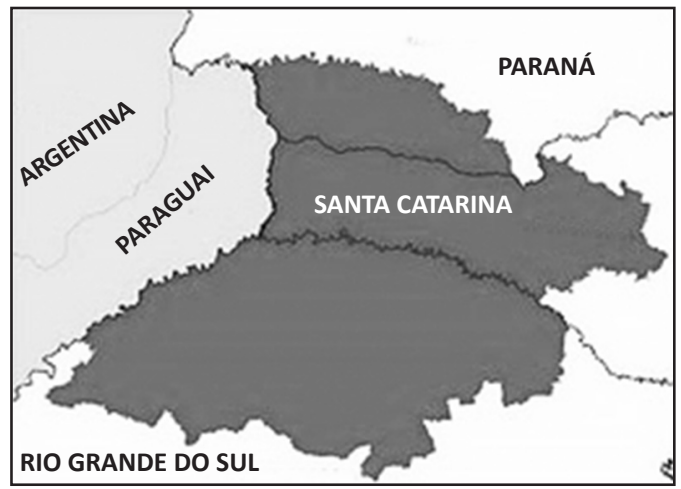

Fonte: Mesomercosul (2013).

Para Damo (2006), a Mesorregião possui identidade histórica própria, forjada desde a chegada dos imigrantes na Região Sul, sobretudo no Rio Grande do Sul, quando houve necessidade de as famílias agirem em conjunto, em favor de seus interesses individuais e coletivos. Outro fator determinante na identidade mesorregional é a inserção nas bacias hidrográficas do Rio Uruguai (contemplando municípios gaúchos e catarinenses) e do Rio Paraná (contemplando municípios paranaenses), com semelhanças físicas e socioeconômicas que reforçam sua identidade histórica e cultural (SOLDI et al., 2007).

No decorrer do tempo, desenvolveu-se, na Mesorregião Grande Fronteira do MERCOSUL, uma articulação de diferentes atores sociais, determinando uma participação política e social. Como reflexo, surgiu uma rede de associações e conselhos municipais. Atualmente, a Mesorregião abriga sete Conselhos Regionais de Desenvolvimento (COREDES), envolvendo os municípios do Rio Grande do Sul, dez associações municipais de Santa Catarina, além de associações municipais paranaenses (MESOMERCOSUL, 2013).

Para o seu desenvolvimento, a Mesorregião apresenta tradição do associativismo; entretanto, destacam-se alguns entraves para o crescimento, como a grande dificuldade dos municípios pequenos, isoladamente, terem acesso a recursos financeiros e humanos qualificados; a escassez de recursos voltados para o desenvolvimento das regiões; a necessidade de uma gestão eficiente, que potencialize os recursos disponíveis; a crescente perda de dinamismo da economia regional, frente ao contexto de globalização e competitividade; a dificuldade de inserção da pequena propriedade rural no mercado e as precárias condições de moradia de parcela significativa da população, com deficiências de saneamento básico, acesso à saúde e educação. Como consequência dos fatores elencados, advém a baixa capacidade de absorção de mão de obra e a retenção da população, gerando êxodo rural e emigração regional (MESOMERCOSUL, 2013): 
Verifica-se, também, uma grande disparidade da Mesorregião Grande Fronteira do Mercosul em relação ao restante da Região Sul. Apesar da Mesorregião compreender um quarto do território e abrigar um quarto da população da região, o seu Produto Interno Bruto representa pouco mais que um décimo do Produto Interno Bruto da Macrorregião Sul. Além disso, o PIB per capita da Mesorregião (US\$ 3.285) é 40\% menor que o da Região Sul - US\$ 5.320.

A despeito da existência de alguns centros industriais na Mesorregião Grande Fronteira do MERCOSUL, com relativa diversificação, a agropecuária e a agroindústria constituem a base da sua estrutura produtiva. Sendo assim, seus principais produtos são grãos, suínos, aves, bovinos de corte e leite; frutas, erva-mate e fumo. Constitui-se, primordialmente, de propriedades rurais de até 100 hectares, denotando uma vulnerabilidade excessiva (MESOMERCOSUL, 2013):

Em síntese, a caracterização sociocultural, política e geoeconômica da Mesorregião Grande Fronteira do Mercosul demonstra, de um lado, um conjunto de problemas econômicos e sociais que precisam ser atacados pela parceria entre o Poder Público, setor privado e organizações da sociedade civil, e, de outro, o grande potencial de alavancagem do desenvolvimento a partir da potencialização do seu capital social e natural. Dessa forma, fazem-se necessárias ações que reforcem o processo de cooperação, materializando esses esforços em uma ação de desenvolvimento integrado e sustentável, pela mobilização do potencial de desenvolvimento endógeno e objetivando a redução das desigualdades econômicas, sociais e regionais.

Os territórios, com os sistemas de produção e as relações sociais que historicamente lhes dão identidade, delimitam e condicionam os comportamentos dos atores, mas estes, nas suas condutas, exibem espontaneidade e uma razão prática, quer dizer, voluntarismo. Essa combinação de "enraizamento" e voluntarismo integra o cerne do debate sobre desenvolvimento local e sustentável com base em estudos sobre aglomerações produtivas. Se, diante da globalização, alguns locais se saem melhor do que outros, os atributos dos bem-sucedidos - aí incluídos os níveis alcançados de mobilização social - figuram entre os principais elementos a serem destacados nas considerações sobre o desenvolvimento. Entre esses elementos, desponta a participação efetiva e estratégica dos agentes locais (os próprios alvos das medidas de promoção) no reconhecimento dos problemas, na sua hierarquização e na proposição de medidas, assim como no planejamento e na implementação das ações (LINS, 2007).

\section{Considerações finais}

Este estudo buscou analisar os processos que culminaram com a implantação das Mesorregiões Diferenciadas, mais especificamente a Mesorregião Grande Fronteira do MERCOSUL. Cristalizado pela Política Nacional de Desenvolvimento Regional (PNDR), em cuja escala a mesorregional é prioritária, permitiu a criação dos espaços contemplados pelo Programa de Promoção da Sustentabilidade de Espaços Sub-Regionais (PROMESO).

Desta forma, foi analisada a política pública que possibilitou os fatores desencadeadores e legais para a criação da Mesorregião, seu contexto socioeconômico e as possibilidades de desenvolvimento endógeno, os agentes envolvidos no processo e o 
empoderamento dos atores em função desta região diferenciada.

O desenvolvimento de uma nação perpassa, obrigatoriamente, pela solidez de suas instituições, resultando numa política pública capaz de estimular o desenvolvimento socioeconômico. Assim sendo, na sua concepção e etapas iniciais de uma política pública, cujo objetivo basilar é a contribuição para a transformação de uma região do país, apresenta-se como uma realidade, uma vez que a demanda por políticas públicas assertivas foi atendida. Os resultados da implantação desta Mesorregião são perceptíveis.

Em resumo, a descentralização de funções do Estado e a visibilidade alcançada por certas dinâmicas produtivas localizadas contribuíram para outorgar ao nível local uma considerável expressão na abordagem do desenvolvimento. Esses vetores mostram-se interdependentes: a descentralização é encorajada pelos resultados em nível de aglomerado - se o dinamismo emerge de atributos principalmente locais, é o plano territorial de intervenção que deve ser priorizado -, e a performance localizada revela-se estimulada por ações públicas voltadas às necessidades do tecido produtivo local (LINS, 2007, p. 9).

Em virtude da incipiência da política pública implantada, sugere-se a importância da realização futura de outros estudos, como o apresentado neste artigo, a fim de levantar os impactos ocasionados pelo PROMESO, em especial o da Mesorregião Grande Fronteira do MERCOSUL.

\section{Referências}

BANDEIRA, Pedro. Participação, articulação de atores sociais e desenvolvimento regional. Brasília: IPEA, 1999.

BRASIL. Ministério da Integração Nacional. Programa de Promoção da Sustentabilidade de Espaços Sub-Regionais: PROMESO. Brasília, 2009.

. Ministério da Integração Nacional. Secretaria de Programas Regionais. Disponível em: <http://www.mi.gov.br/programas/programasregionais/index.asp? area=spr_mes_fronteira $>$. Acesso em: 20 jan. 2013.

DAMO, Marcia Regina Sartori. Análise da descentralização administrativa do governo do estado e os efeitos da fragmentação territorial no oeste catarinense. Florianópolis: UFSC, 2006.

FELICETTI, Vera Lucia; MOROSINI, Marília Costa. Equidade e iniquidade no ensino superior: uma reflexão. In: Revista Ensaio: avaliação e políticas públicas em educação, Rio de Janeiro, v. 17, n. 62, p. 9-24, jan./mar. 2009.

GIL, Antônio Carlos. Como Elaborar Projetos de Pesquisa. 5. ed. São Paulo: Atlas, 2010.

LINS, Hoyêdo Nunes. Um diálogo com o tema do desenvolvimento local e sustentável em Santa Catarina. I Encontro de Economia Catarinense. Universidade Federal de Santa Catarina, Florianópolis, 2007.

MESOMERCOSUL. Federalismo, Cooperativismo e Organização social para o desenvolvimento. 2013. Disponível em: <http://www.mesomercosul.org.br/ >. Acesso em: 23 maio 2013.

SOLDI, Valdir et al. Projeto: Universidade Federal da Mesomercosul. Florianópolis: UFSC, 2007. 